\title{
Risk factors for clinical mastitis, ketosis, and pneumonia in dairy cattle on organic and small conventional farms in the United States
}

\author{
R. M. Richert, ${ }^{\star}$ K. M. Cicconi, $†$ M. J. Gamroth, $\ddagger$ Y. H. Schukken, $†$ K. E. Stiglbauer, $\ddagger$ and P. L. Ruegg ${ }^{* 1}$ \\ *Department of Dairy Science, University of Wisconsin, Madison 53706 \\ †Quality Milk Production Services, Cornell University, Ithaca, NY 14850 \\ ‡Department of Animal Sciences, Oregon State University, Corvallis 97331
}

\begin{abstract}
The US regulations for production of organic milk include a strict prohibition against the use of antimicrobials and other synthetic substances. The effect of these regulations on dairy animal health has not been previously reported. The objective of this study was to characterize disease detection and identify risk factors for selected diseases on organic (ORG) and similarly sized conventional $(\mathrm{CON})$ farms. Dairy herds $(\mathrm{n}=292)$ were enrolled across 3 states (New York, Oregon, Wisconsin) with CON herds matched to ORG herds based on location and herd size. During a single herd visit, information was collected about herd management practices and animal disease occurring in the previous $60 \mathrm{~d}$, and paperwork was left for recording disease occurrences during $60 \mathrm{~d}$ after the visit. For analysis, CON herds were further divided into grazing and nongrazing. Poisson regression models were used to assess risk factors for rate of farmer-identified and recorded cases of clinical mastitis, ketosis, and pneumonia. An increased rate of farmer-identified and recorded cases of clinical mastitis was associated with use of CON management, use of forestripping, presence of contagious pathogens in the bulk tank culture, proactive detection of mastitis in postpartum cows, and stall barn housing. An increased rate of farmer-identified and recorded cases of ketosis was associated with having a more sensitive definition of ketosis, using stall barn housing, and feeding a greater amount of concentrates. An increased rate of farmer-identified and recorded cases of pneumonia was associated with a lack of grazing, small or medium herd size, and Jersey as the predominant breed. Overall, disease definitions and perceptions were similar among grazing systems and were associated with the rate of farmer-identified and recorded cases of disease.
\end{abstract}

Key words: organic management, clinical mastitis, ketosis, pneumonia

Received July 25, 2012.

Accepted March 6, 2013.

${ }^{1}$ Corresponding author: plruegg@wisc.edu

\section{INTRODUCTION}

Organic (ORG) dairy farms in the United States often have characteristics that differ from conventional $(\mathbf{C O N})$ dairy farms, including a smaller herd size, use of non-freestall housing, and grazing-based diets (Zwald et al., 2004; Sato et al., 2005; Pol and Ruegg, 2007). These management factors have also been associated with incidence and prevalence of various diseases, and therefore may confound the potential effect of ORG management on disease incidence. In a US survey $(\mathrm{n}=$ 858 farms) that assessed antimicrobial usage for several common diseases of dairy cattle, small herd size (30-99 cows) was associated with a greater within-herd prevalence of any given disease (Hill et al., 2009). Likewise, Valde et al. (1997) reported that Norwegian dairy herds that used stall barn housing $(\mathrm{n}=59)$ had greater incidence rates of clinical mastitis and ketosis compared with herds housed in freestalls $(\mathrm{n}=533)$. Researchers have not consistently linked grazing to improvements in cow health. In one study, grazing was associated with a decreased risk of metritis (Bruun et al., 2002), whereas Barkema et al. (1999) reported that overnight pasturing of dairy cattle was associated with an increased incidence rate of Escherichia coli clinical mastitis.

It is difficult to determine how the definition and perception of disease by animal caregivers influences the incidence and detection of disease. Attitudes about mastitis have been associated with the incidence rate of clinical mastitis (Nyman et al., 2007; Jansen et al., 2009). Organic and CON farmers have different options available for treating most diseases, which may influence disease perception. For example, the availability of efficacious treatments and previous experience with alternative treatments might influence farmers' perception about disease control (Vaarst et al., 2002). Hardeng and Edge (2001) speculated that reduced rates of veterinary-treated disease in cows on ORG compared with CON farms may be due to differing attitudes and disease management practices, but research in this area is lacking.

Researchers comparing rates of clinical mastitis on ORG and CON farms often report less disease on or- 
ganic farms (Sato et al., 2005; Pol and Ruegg, 2007; Valle et al., 2007). The occurrence of less clinical mastitis among ORG farms has been attributed to reduced milk production (Valle et al., 2007) and improved cow cleanliness (Ellis et al., 2007). However, the farmer's definition and perception of mastitis may result in an apparent difference in the rate of clinical mastitis. Pol and Ruegg (2007) documented differences in monitoring mastitis and definition of cure of mastitis after treatment between ORG and CON farmers in Wisconsin. In this study, visual observation of abnormal milk was used to detect mastitis by $90 \%$ of $\mathrm{CON}$ farmers in contrast to only $45 \%$ of ORG farmers. Organic farmers relied more on other methods for detecting mastitis, such as visualization of swollen quarters, California Mastitis Test results, and observation of abnormal milk on the milk filter (Pol and Ruegg, 2007; Ruegg, 2009). Swedish researchers reported an association between the definition of mastitis and the incidence rate of veterinary treatment (Nyman et al., 2007). Farmers who characterized mastitis based on mild symptoms (such as abnormal milk only) reported a greater incidence rate of veterinary-treated mastitis compared with farmers who treated cows only after observation of systemic signs.

Risk factors for metabolic diseases of dairy cows (such as milk fever and ketosis) include stage of lactation, parity, milk production, and nutritional management (Radostits et al., 2007; Smith, 2008; LeBlanc, 2010). The incidence of ketosis was less on ORG compared with CON farms and was attributed to reduced milk production among ORG herds (Hardeng and Edge, 2001) and different threshold criteria for calling a veterinarian (Bennedsgaard et al., 2003a). Studies comparing disease rates and risk factors between cattle on ORG and CON farms must account for potential differences in perception. The objective of this study was to characterize farmers' perceptions of disease and identify risk factors for disease on ORG, CON grazing, and CON nongrazing dairy farms.

\section{MATERIALS AND METHODS}

\section{Data Collection}

Information about herd recruitment and data collection has been previously described (Richert et al., 2013; Stiglbauer et al., 2013). In brief, farms $(\mathrm{n}=292)$ were recruited between April 2009 and April 2011 from dairy herds located in New York State (NY), Oregon (OR), and Wisconsin (WI). All herds were required to have a minimum of 20 cows and must have been shipping milk for at least 2 yr. Organic herds must have been shipping certified ORG milk for at least 2 yr. During a single farm visit, a questionnaire on management practices was administered (available at http://milkquality. wisc.edu/organic-dairies/project-c-o-w/) and information was collected on occurrence of disease during the retrospective period, which was defined as the $60 \mathrm{~d}$ before the farm visit. Prospective data were collected for the 60-d period after the farm visit using defined recording forms. Farmers were instructed to recall or record information about all sick animals, regardless of administration of treatment. Study approval was obtained from the Institutional Review Board and Animal Care and Use Committee at Oregon State University.

During the farm visit, lactating cows were scored for udder hygiene according to the method of Schreiner and Ruegg (2003). Udder hygiene scores (UHS) were obtained from all lactating cows (up to 50), or for larger herds, a randomly selected, representative sample of $20 \%$ of lactating cows was scored. Samples of bulk milk were collected by study personnel and sent to a single laboratory in NY for analysis. Bulk milk samples were tested for SCC, plate loop count (PLC), and mastitis pathogens including Mycoplasma.

\section{Definitions of Variables}

For all analyses, disease definitions were herd specific, and the selected risk factors eligible for inclusion in the analysis were rolling herd average (RHA), percentage of lactating and dry cows in third or greater lactation, percentage of lactating herd in early lactation (<90 DIM), herd size category (20-99 lactating and dry cows, 100-199, $\geq 200)$, predominant breed $(>50 \%$ of cows; Holstein, Jersey, other), season of herd visit (spring, summer, autumn, winter), primary housing for lactating cows at the time of herd visit (freestall, group pen, pasture or drylot, stall barn), performance of any routine postpartum cow exam (yes, no), likelihood of farmer to call a veterinarian for an off-feed cow (low, medium, high), rate of routinely scheduled veterinary visits per 100 cows per year (none, few, some, many), site (NY, OR, WI), utilization of grazing ( $\geq 30 \%$ of DMI for lactating cows was obtained from pasture during the grazing season; yes, no), and management system (ORG, CON). Management system and utilization of grazing were combined to create a new 3-level variable (grazing system): (1) ORG, (2) CON grazing (CONGR), and (3) CON nongrazing (CON-NG).

Cases of clinical mastitis were identified and recorded by the farmer during the retrospective or the combined (retrospective and prospective) data collection period. Cow-days at risk for clinical mastitis were calculated for each herd by multiplying the number of lactating cows at the time of the herd visit by $60 \mathrm{~d}$ if data were available for only the retrospective data collection pe- 
riod or $120 \mathrm{~d}$ if data were available for the combined data collection period. Rate of clinical mastitis was measured per 305 lactating cow-days at risk. Selected risk factors considered for inclusion in the analysis of rate of farmer-identified and recorded cases of clinical mastitis were SCC of the bulk milk sample ( $\log _{10}$ cells/ $\mathrm{mL})$, PLC of the bulk milk sample $\left(\log _{10} \mathrm{cfu} / \mathrm{mL}\right)$, presence of contagious pathogens in the bulk milk culture (yes, no), proportion of lactating cows with 3 or fewer quarters (\%), proportion of lactating cows with a UHS score of 1 or 2 at the time of the herd visit (\%), use of routine forestripping during milking procedure (yes, no), use of routine predipping during milking procedure (yes, no), use of routine postdipping during milking procedure (yes, no), use of a complete milking routine (forestrip, predip, dry, postdip; yes, no), primary milking facility (flat parlor, double-sided pit parlor, other parlor, stall barn), percentage of cases of subclinical mastitis that were treated $(<50,50-99,100 \%)$, listing "check for mastitis" as 1 of the 3 primary symptoms used to screen for potentially ill cows (yes, no), routine checking for mastitis as part of postpartum cow exams (yes, no), routine use of cowside methods of measuring SCC (yes, no), removal of udder hair using routine singeing (yes, no), and inclusion of any of the following in the farmer's definition of mastitis: (1) observation of abnormal milk (every milking, infrequent, none), (2) observation of garget on the milk filter (yes, no), (3) high SCC on DHIA or California Mastitis Test (yes, no), (4) observation of swelling, heat, or redness in the quarter (yes, no), (5) observation of systemic signs of illness in the cow (yes, no).

Cases of ketosis were identified and recorded by the farmer during the retrospective or combined data collection period. Cow-days at risk for ketosis were calculated for each herd by multiplying the number of lactating cows at the time of the herd visit by $60 \mathrm{~d}$ if data were available for only the retrospective data collection period or $120 \mathrm{~d}$ if data were available for the combined data collection period. Rate of ketosis was measured per 305 lactating cow-days at risk. Selected risk factors considered for inclusion in the analysis of rate of farmer-identified and recorded cases of ketosis were amount of grain fed per cow per day $(\mathrm{kg})$, routine checking for ketosis as part of postpartum cow exams (yes, no), farmer perceiving ketosis to occur on farm (yes, no), and inclusion of any of the following in the farmer's definition of ketosis: (1) positive urine, milk, or blood ketone test (yes, no), (2) depressed attitude (yes, no), (3) decreased milk production (yes, no), (4) smell of ketones (yes, no), (5) decreased feed intake (yes, no), (6) trembling, chewing, or other signs of nervous ketosis (yes, no), (7) weight loss (yes, no), (8) decreased or stiff manure (yes, no).
Cases of pneumonia were identified and recorded by the farmer during the retrospective or combined data collection period. Cow-days at risk for pneumonia were calculated for each herd by multiplying the number of lactating and dry cows at the time of the herd visit by $60 \mathrm{~d}$ if data were available for only the retrospective data collection period or $120 \mathrm{~d}$ if data were available for the combined data collection period. Rate of farmer-identified and recorded cases of pneumonia was measured per 365 cow-days at risk. Selected risk factors considered for inclusion in the analysis of rate of farmer-identified and recorded pneumonia were farmer perceiving pneumonia to occur on their farm (yes, no) and inclusion of any of the following in the farmer's definition of pneumonia: (1) presence of a cough (yes, no), (2) presence of nasal discharge (yes, no), (3) decreased milk production (yes, no), (4) dyspnea (yes, no), (5) decreased feed intake (yes, no), (6) presence of fever (yes, no), (7) depressed attitude (yes, no).

\section{Statistical Procedures}

The herd was the unit of analysis. Descriptive statistics were used to verify data accuracy, detect missing data, and observe frequency distributions. The PROC FREQ (SAS Institute, 2011) was used to perform all Chi-squared analyses. When expected values in at least one cell were $<5$, the Fisher's exact test was used. Statistical significance was defined as $P \leq 0.05$ for all analyses. Data were tested for presence of selection bias for completion of the data collection period. Wilcoxon rank-sum tests were performed using PROC NPAR1WAY (SAS Institute, 2011) to determine if herd size and RHA were independent of completion of prospective data forms. Chi-squared analyses were performed to determine if site was independent of completion of prospective data forms. A Cochran-Mantel-Haenszel analysis was performed to determine if grazing system was independent of completion of prospective data forms after adjustment for differences in recruitment by site (Richert et al., 2013).

Chi-squared analyses were performed to determine if each of the following were independent of grazing system: (1) each symptom used as primary method to screen cows for further examination (Table 1), (2) each symptom used in routine screening of postpartum cows (Table 2), and (3) recorded presence of selected diseases on farms (Table 3). In each test, grazing system (ORG, CON-GR, CON-NG) formed the columns of the table and presence of symptom or disease (yes, no) formed the rows of the table.

The PROC NPAR1WAY (SAS Institute, 2011) was used to perform Wilcoxon rank-sum tests to determine if percentage of cows with 3 or fewer quarters, rate of 
Table 1. Distribution (no.; \% in parentheses) of the 3 primary symptoms used by farmers to screen for cows that are potentially ill and require further examination in herds located in New York State, Oregon, and Wisconsin

\begin{tabular}{lccccc}
\hline & & \multicolumn{3}{c}{ Grazing system } \\
\cline { 3 - 4 } & \multicolumn{1}{c}{$\begin{array}{c}\text { Overall } \\
\text { Primary symptom }\end{array}$} & $\begin{array}{c}\text { Organic } \\
(\mathrm{n}=192) \\
(\%)\end{array}$ & $\begin{array}{c}\text { Conventional } \\
\text { grazing } \\
(\mathrm{n}=36)(\%)\end{array}$ & $\begin{array}{c}\text { Conventional } \\
\text { nongrazing } \\
(\mathrm{n}=64)(\%)\end{array}$ & $P$-value \\
\hline Abnormal manure & $40(14)$ & $25(13)$ & $5(13)$ & $10(16)$ & 0.87 \\
Abnormal milk or swollen udder & $38(13)$ & $26(14)$ & $1(3)$ & $11(17)$ & 0.11 \\
Cold ears & $26(9)$ & $18(9)$ & $4(11)$ & $4(6)$ & 0.62 \\
Cow is lame or moves slowly & $95(33)$ & $64(33)$ & $14(39)$ & $17(27)$ & 0.42 \\
Decreased feed intake & $212(73)$ & $135(70)$ & $31(86)$ & $46(72)$ & 0.15 \\
Decreased milk yield & $110(38)$ & $62(32)$ & $17(47)$ & $31(48)$ & 0.03 \\
Depressed attitude or behavior & $185(63)$ & $124(65)$ & $25(69)$ & $36(56)$ & 0.35 \\
Other method & $65(22)$ & $48(25)$ & $3(8)$ & $14(22)$ & 0.09 \\
Suspect increased body temperature & $59(20)$ & $37(19)$ & $5(14)$ & $17(27)$ & 0.27 \\
\hline
\end{tabular}

" Other method" included uterine discharge or odor, poor haircoat, loss of body condition, difficulty breathing.

clinical mastitis, rate of ketosis, and rate of pneumonia were independent of grazing system. The PROC GLM (SAS Institute, 2011) was used to perform 7 ANOVA tests to determine if RHA, proportion of lactating and dry cows in third or greater lactation, proportion of lactating cows in early lactation, proportion of lactating cows with a UHS of 1 or 2, amount of grain fed, bulk tank SCC, and bulk tank PLC were each independent of grazing system. Chi-squared analyses were used to determine if each explanatory variable with a categorical distribution was independent of grazing system. In each test, grazing system (ORG, CON-GR, CON-NG) formed the columns of the table and categories of each explanatory variable (Table 4 ) formed the rows of the tables.

All multivariate models were built using a manual process that incorporated the biological and statistical relevance of each variable. Initially, all biologically relevant variables were tested for univariate associations among predictor variables using Chi-squared (for categorical variables) or correlation analysis (for continuous variables). If variables were highly associated, the more biologically relevant variable was selected for further analysis. For all models, after initial screening, variables were further assessed by screening for unconditional associations between each selected risk factor and the relevant outcome variable. For each model, risk factors that were unconditionally associated with the outcome variable at $P \leq 0.20$ were offered for further multivariate modeling. Both forward and backward variable selection procedures were used to select the variables that remained in the final models. Confounding was assessed by examining the effect of each variable on the rate ratios of other explanatory variables (Dohoo et al., 2003). No variables included in any final model resulted in substantial changes among rate ratios of other explanatory variables, indicating that confounding was not a problem. Biologically relevant first-order interactions among variables were offered for backward and forward variable selection to construct

Table 2. Symptoms observed (no.; \% in parentheses) by farmers to routinely screen postpartum cows in herds located in New York State, Oregon, and Wisconsin

\begin{tabular}{|c|c|c|c|c|c|}
\hline \multirow[b]{2}{*}{ Symptom } & \multirow[b]{2}{*}{ Overall } & \multicolumn{3}{|c|}{ Grazing system } & \multirow[b]{2}{*}{$P$-value } \\
\hline & & $\begin{array}{c}\text { Organic } \\
(\mathrm{n}=192)\end{array}$ & $\begin{array}{l}\text { Conventional } \\
\text { grazing } \\
(\mathrm{n}=36)\end{array}$ & $\begin{array}{l}\text { Conventional } \\
\text { nongrazing } \\
(\mathrm{n}=64)\end{array}$ & \\
\hline Abnormal milk or warm udder & $180(62)$ & $125(65)$ & $20(56)$ & $35(55)$ & 0.24 \\
\hline Cow is weak or down & $45(15)$ & $29(15)$ & $7(19)$ & $9(14)$ & 0.76 \\
\hline Decreased feed intake & $97(33)$ & $53(28)$ & $18(50)$ & $26(41)$ & 0.01 \\
\hline Decreased milk yield & $37(13)$ & $21(11)$ & $7(19)$ & $9(14)$ & 0.34 \\
\hline Depressed attitude or behavior & $20(7)$ & $14(7)$ & $0(0)$ & $6(9)$ & 0.18 \\
\hline Ketosis test & $17(6)$ & $7(4)$ & $4(11)$ & $6(9)$ & 0.06 \\
\hline Measure body temperature & $46(16)$ & $15(8)$ & $9(25)$ & $22(34)$ & $<0.001$ \\
\hline Other method & $30(10)$ & $20(10)$ & $4(11)$ & $6(9)$ & 0.96 \\
\hline Retained placenta & $85(29)$ & $45(23)$ & $14(39)$ & $26(41)$ & 0.01 \\
\hline Perform routine screening of postpartum cows & $247(85)$ & $162(84)$ & $30(83)$ & $55(86)$ & 0.93 \\
\hline
\end{tabular}




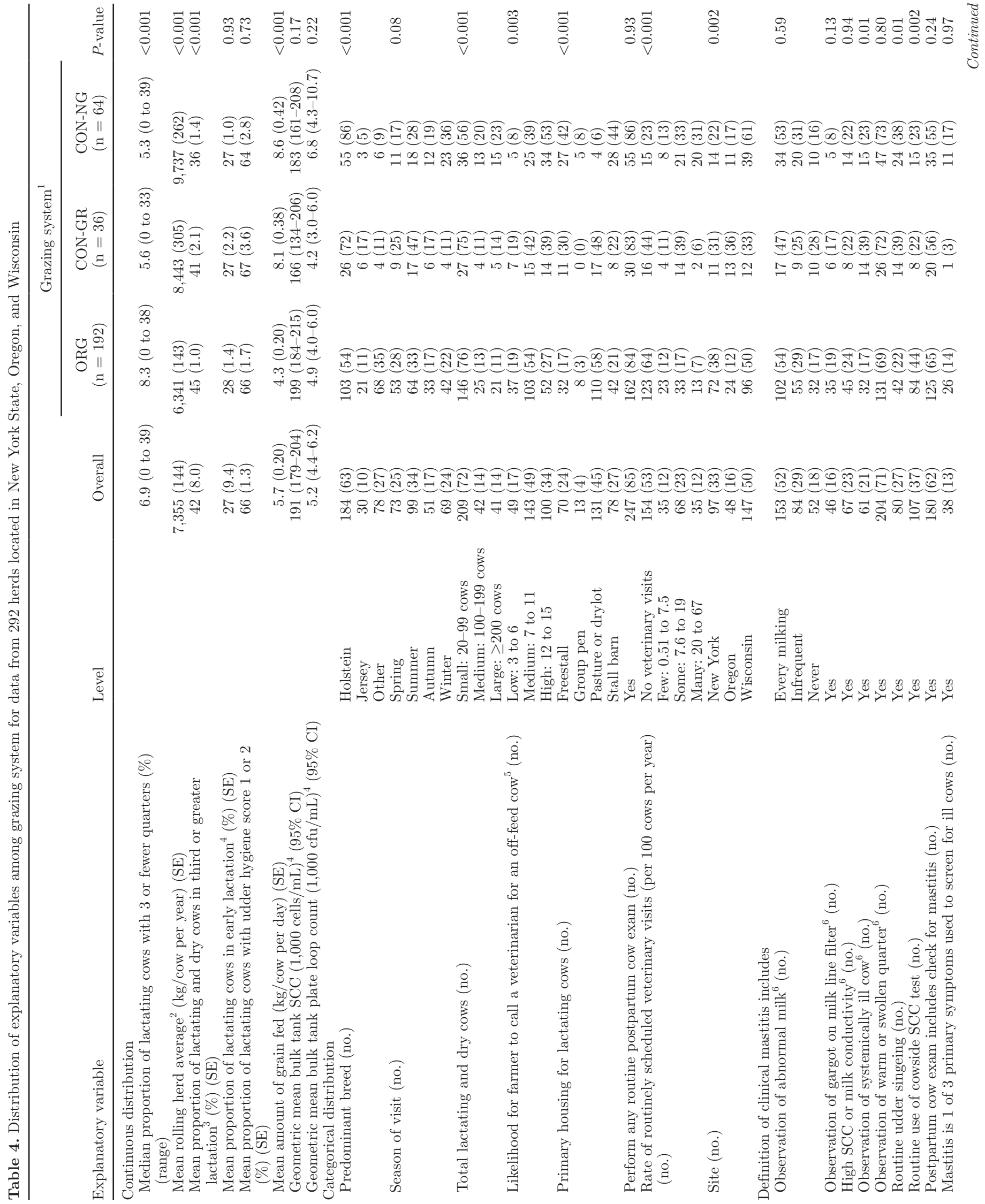




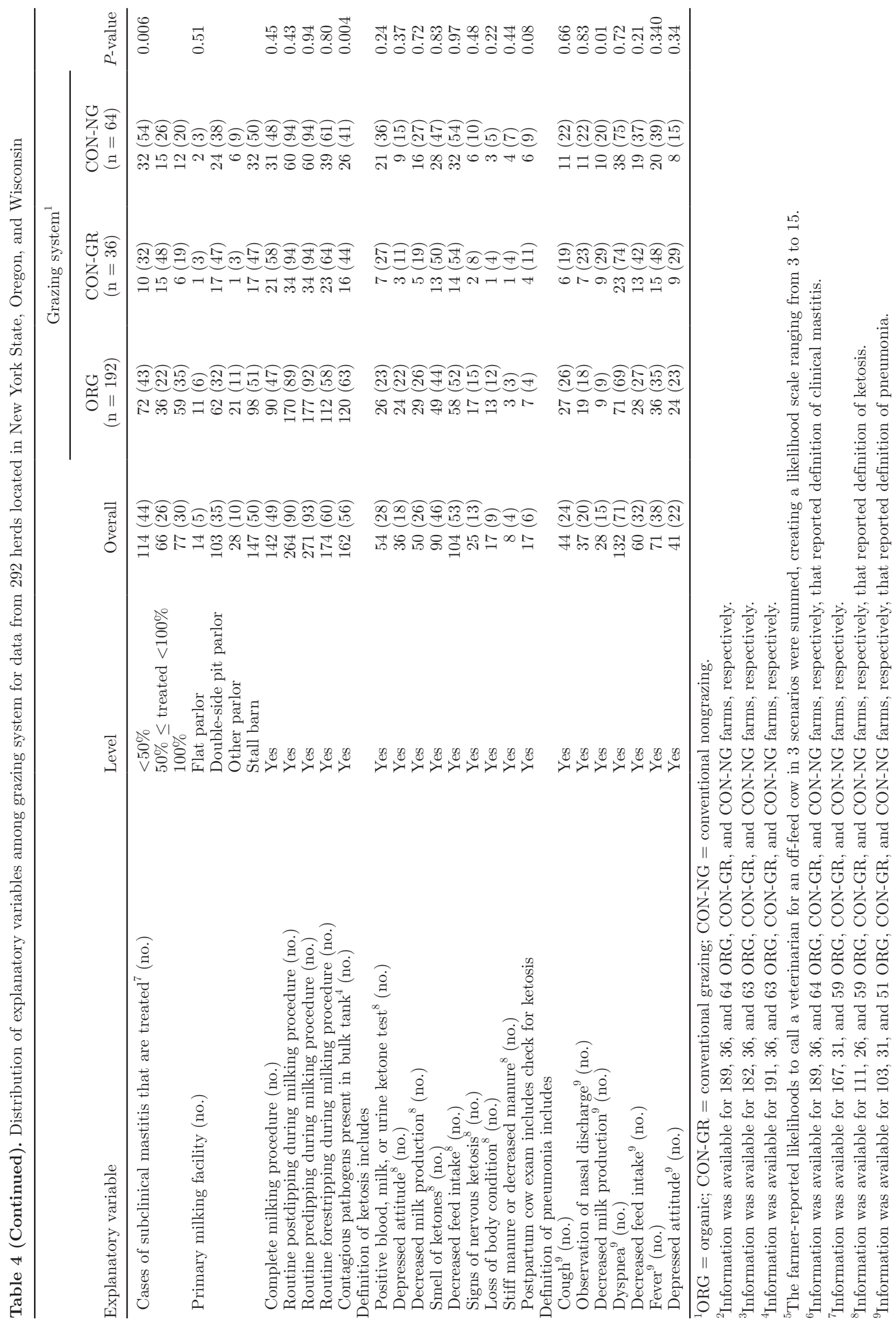


(ketosis and pneumonia) using backward and forward variable selection procedures.

\section{RESULTS}

Retrospective information about sick cows was collected on $95 \mathrm{NY}, 40 \mathrm{OR}$, and $147 \mathrm{WI}$ farms, and prospective information about sick cows was returned by $29(30 \%)$ of these NY, $31(78 \%)$ of these OR, and 118 $(80 \%)$ of these WI farmers, for a total of 178 farmers completing the combined data collection period for sick cows. Herd size and RHA were not associated with completion of the data collection period. After adjusting for state, grazing system was not associated with completion of the data collection period for veterinary visits or sick cows $(P=0.12)$.

Most farmers reported reduced feed intake and depressed attitude as primary observations used to screen for potentially ill cows (Table 1). Organic farmers relied less often on observation of decreased milk yield compared with CON-GR and CON-NG farmers. Overall, $85 \%$ of farmers reported performing examinations on postpartum cows, with ORG farmers less likely than CON-GR and CON-NG farms to examine cows for retained placenta, abnormal body temperature, and decreased feed intake (Table 2).

During the 120-d combined data collection period, identification and recording of at least one case of calf diarrhea, displaced abomasum, ketosis, metritis, adult cow pneumonia, and calf pneumonia was associated with grazing system (Table 3). Of all farmers, organic farmers were less likely to identify and record at least

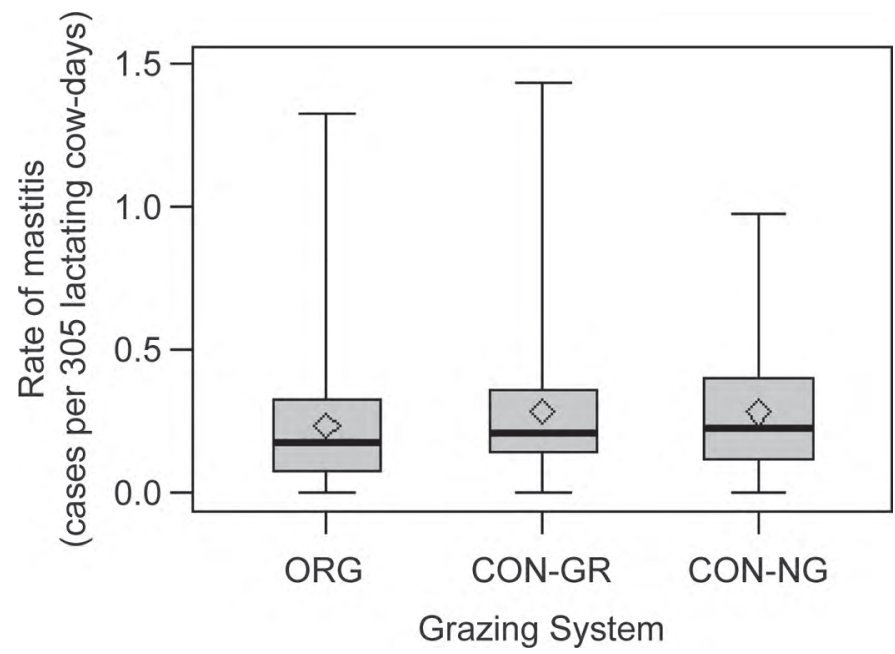

Figure 1. Distribution of rate of farmer-identified and recorded clinical mastitis (cases per 305 lactating cow-days) by grazing system for data collected from 183 organic (ORG), 34 conventional grazing (CON-GR), and 59 conventional nongrazing (CON-NG) herds located in New York State, Oregon, and Wisconsin. Rate of mastitis tended to differ among grazing systems $(P=0.066)$. one case of ketosis or calf diarrhea compared with CON-GR and CON-NG farmers. Displaced abomasum, metritis, and pneumonia (in both cows and calves) were each reported to occur in cattle on fewer ORG and more CON-NG farms compared with CON-GR farms. Farmers either routinely administered preventative treatments or perceived intestinal parasites as a problem approximately half as frequently on ORG compared with CON-GR and CON-NG farms.

\section{Characteristics of Enrolled Herds}

Management factors that were associated with grazing system included herd size and RHA $(P<0.001)$, with ORG farms containing the fewest cows and having the least RHA, and CON-NG farms containing the most cows and having the greatest RHA (Table 4). The proportion of lactating cows with 3 or fewer quarters was greater on ORG compared with CON-GR and CON-NG farms $(P<0.001)$. The proportion of lactating and dry cows in third or greater lactation was least on CON-NG farms, intermediate on CON-GR farms, and greatest on ORG farms $(P<0.001)$. Organic farmers fed approximately half as much grain as CON-GR and CONNG farmers $(P<0.001)$. Holstein was the predominant breed on approximately three-quarters of CON-GR and CON-NG farms compared with about half of ORG farms $(P<0.001)$; other breeds were predominant on about one-third of ORG farms. Conventional nongrazing farmers were equally likely to use freestall or stall barn housing as the primary housing for lactating cows at the time of the herd visit compared with CON-GR and ORG farmers, who were most likely to use pastures or drylots for housing $(P<0.001)$. Organic and CONGR farmers were most likely to report an intermediate likelihood to call a veterinarian for an off-feed cow compared with CON-NG farmers, who were most likely to report a high likelihood $(P=0.003)$. Organic farmers were least likely to have routinely scheduled veterinary visits compared with CON-GR and CON-NG farmers $(P<0.001)$. As expected based on study design, site was associated with grazing system $(P=0.002)$. Routine removal of udder hair using singeing occurred less often $(P=0.01)$ and routine use of cowside SCC tests occurred more often for ORG farmers $(P=0.002)$ compared with CON-GR and CON-NG farmers. Organic farmers were most likely to report treating all cases of subclinical mastitis (using nonantibiotic treatments; $P=0.006)$ and were most likely to have contagious pathogens found upon culture of bulk tank milk $(P=$ 0.004) compared with CON-GR and CON-NG farmers. Conventional grazing farmers were most likely to use observation of a systemically ill cow as part of their definition of clinical mastitis compared with ORG and 
PERCEPTIONS AND RISK FACTORS FOR DISEASE

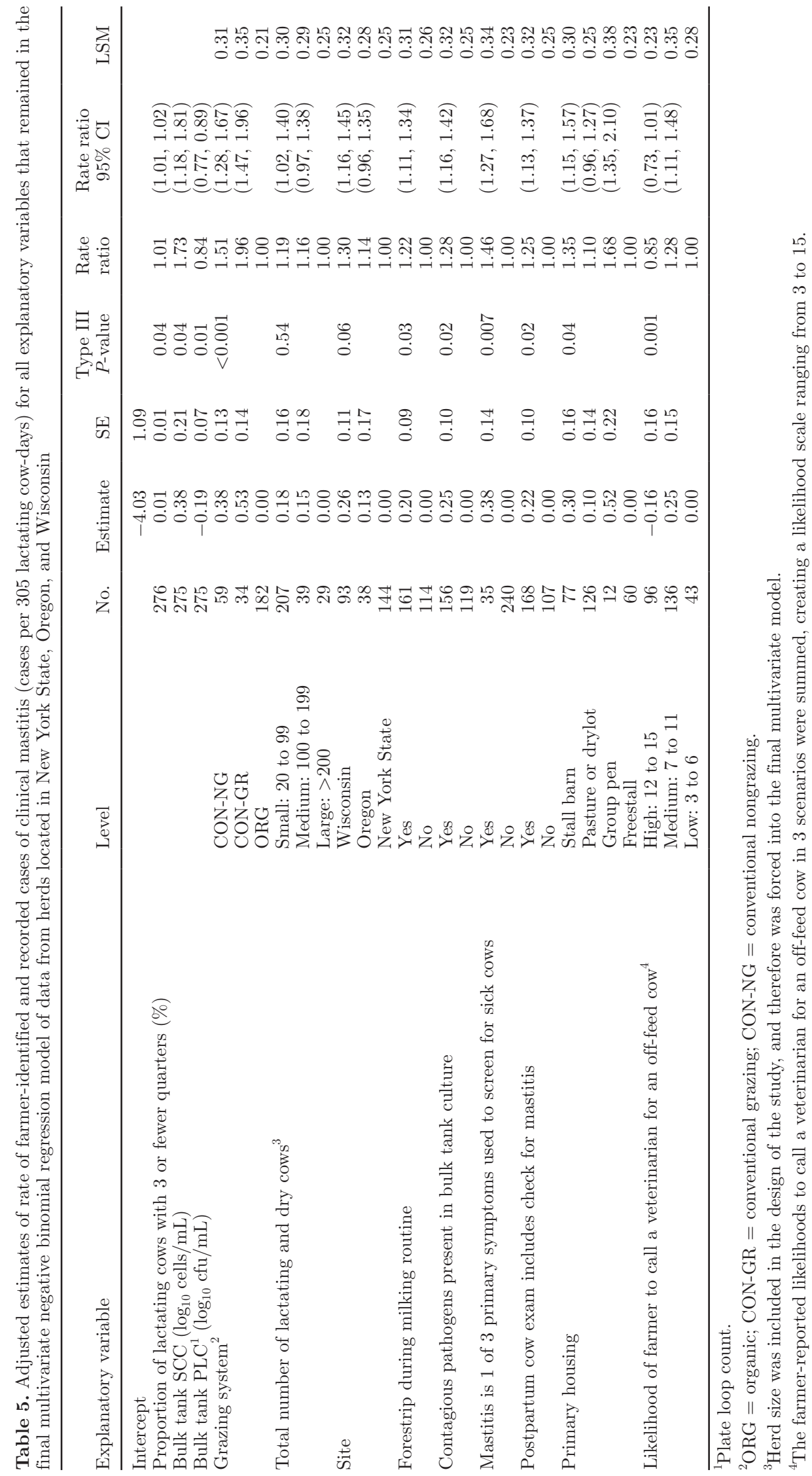

Journal of Dairy Science Vol. 96 No. 7, 2013 


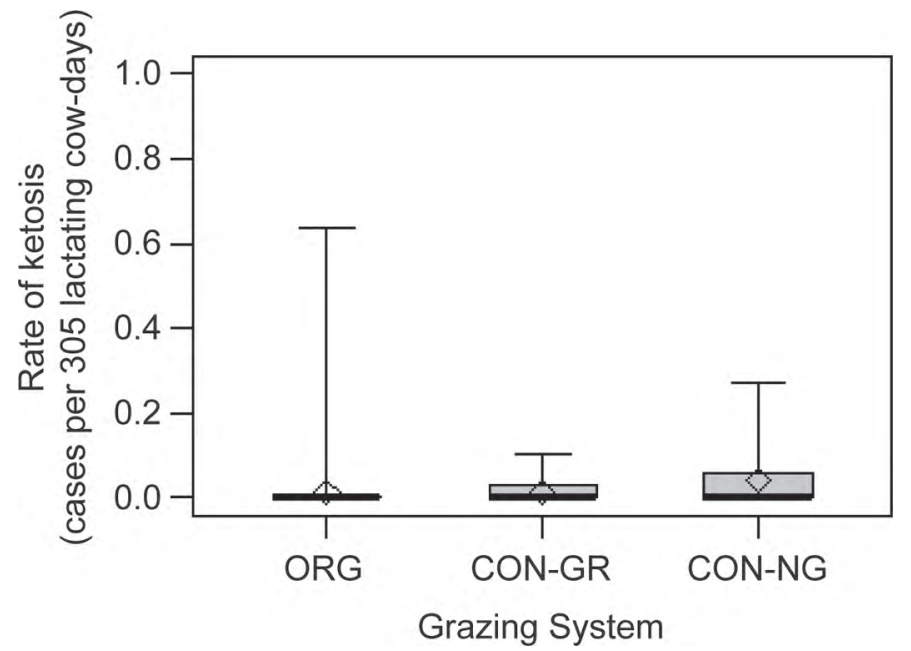

Figure 2. Distribution of rate of farmer-identified and recorded ketosis (cases per 305 lactating cow-days) by grazing system for data collected from 187 organic (ORG), 34 conventional grazing (CON$\mathrm{GR}$ ), and 61 conventional nongrazing (CON-NG) herds located in New York State, Oregon, and Wisconsin. Rate of ketosis differed among grazing systems $(P<0.001)$.

CON-NG farmers $(P=0.01)$. Organic farmers were least likely to use decreased milk production as part of their definition of pneumonia compared with CON-GR and CON-NG farmers $(P=0.01)$.

\section{Rate of Clinical Mastitis}

Data included in the analysis of rate of farmeridentified and recorded cases of clinical mastitis were from farmers who returned data on mastitis incidence for either the retrospective or combined data collection periods $(\mathrm{n}=182$ ORG, $\mathrm{n}=34 \mathrm{CON}-\mathrm{GR}, \mathrm{n}=59 \mathrm{CON}$ NG). Of farmers included in the analysis, 28 (10\%) did not identify and record any cases of mastitis during the data collection period for their farm. The overall rate of farmer-identified and recorded cases of clinical mastitis ranged from 0 to 1.44 cases per 305 lactating cow-days, and tended to be greater in CON-NG herds compared with ORG and CON-GR herds (Figure 1). Explanatory variables unconditionally associated $(P \leq$ $0.20)$ with an increase in rate of farmer-identified and recorded cases of clinical mastitis included a greater proportion of cows with 3 or fewer quarters, lesser proportion of lactating cows with a UHS of 1 or 2, greater bulk tank SCC, and lesser bulk tank PLC. Increased rates of clinical mastitis were also unconditionally associated with the categories CON-GR farm type, small herd size, group and stall barn housing, an intermediate likelihood of calling a veterinarian for an off-feed cow, many routinely scheduled veterinary visits per 100 cows per year, farms located in WI, stall barn milking facilities, presence of contagious pathogens in the bulk tank milk culture, and use of forestripping during the milking routine. A decreased rate of clinical mastitis was unconditionally associated with use of predipping as part of the milking routine. An increased rate of clinical mastitis was unconditionally associated with the farmer reporting mastitis as 1 of the 3 primary symptoms used to screen for ill cows, and inclusion of checking for mastitis as part of a routine postpartum cow exam. The rate of clinical mastitis was not associated with predominant breed present on the farm or with season of herd visit.

Of explanatory variables unconditionally associated with rate of farmer-identified and recorded cases of clinical mastitis, grazing system, herd size, site, forestripping as part of the milking routine, presence of contagious mastitis pathogens in the bulk tank culture, proportion of lactating cows with 3 or fewer quarters, bulk tank SCC, bulk tank PLC, likelihood of calling a veterinarian for an off-feed cow, primary housing for lactating cows, routinely checking for mastitis in postpartum cows, and listing mastitis as 1 of the 3 primary observations used to screen for potentially ill animals remained in the final multivariate model (Table 5). The Akaike information criterion (AIC) of the final multivariate model was 1,412 , with a Pearson $\chi^{2}$ of 282 and 256 degrees of freedom.

Compared with ORG farms, the rates of clinical mastitis were 1.5 and 2.0 times greater on CON-NG and CON-GR farms, respectively. No significant interactions with grazing system remained in the final model. Herds utilizing stall barns and group pens as the primary housing were associated with approximately 1.5 times greater rates of clinical mastitis compared with herds utilizing pasture, drylot, or freestall housing. Farmers who reported mastitis as 1 of the 3 primary signs used to screen for potentially sick cows and farmers who routinely examined postpartum cows for mastitis had approximately 1.5 times greater rates of clinical mastitis in their herds compared with farmers who did not have these characteristics. Farmers who included forestripping in their milking routine and farmers who had contagious mastitis pathogens present in their bulk tank milk had approximately 1.3 times greater rates of mastitis in their herds compared with farmers who did not have these characteristics.

\section{Rate of Ketosis}

Data included in the analysis of rate of farmeridentified and recorded cases of ketosis were from farmers who returned data for either the retrospective or combined data collection periods $(\mathrm{n}=187$ ORG, $\mathrm{n}=$ $34 \mathrm{CON}-\mathrm{GR}, \mathrm{n}=61 \mathrm{CON}-\mathrm{NG}$ ). Of farmers included in the analysis, $221(78 \%)$ did not identify and record 
PERCEPTIONS AND RISK FACTORS FOR DISEASE

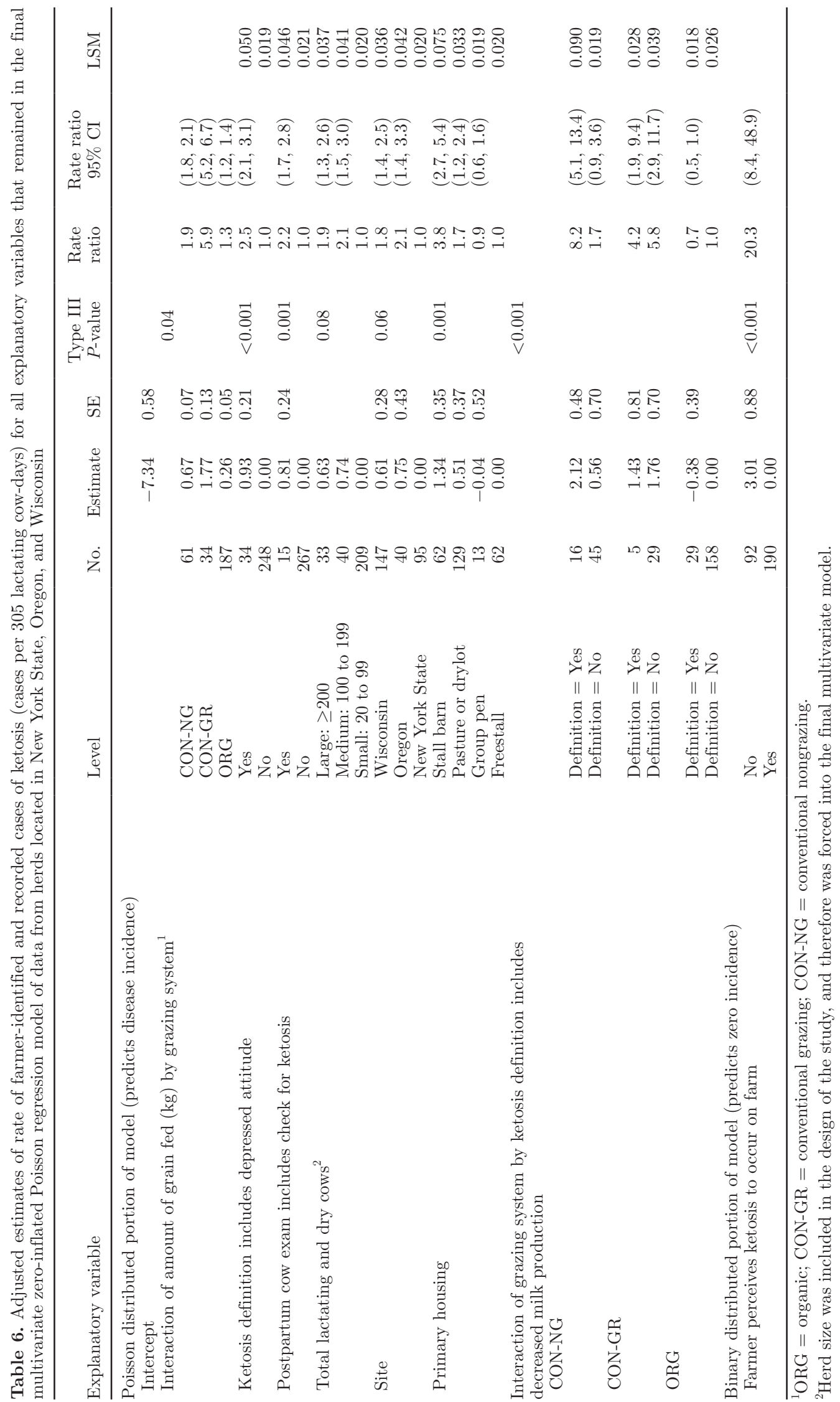




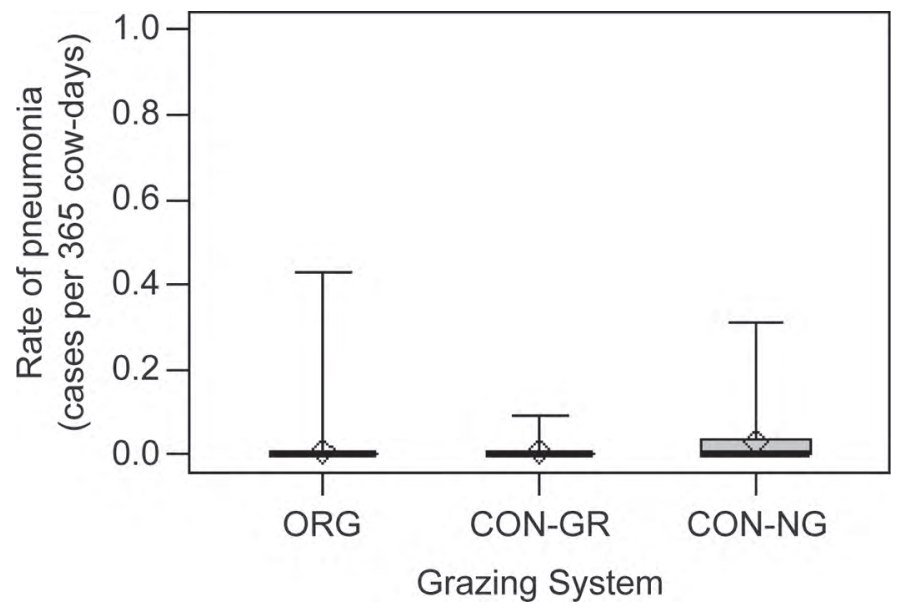

Figure 3. Distribution of rate of farmer-identified and recorded pneumonia (cases per 365 lactating cow-days) by grazing system for data collected from 187 organic (ORG), 34 conventional grazing (CON-GR), and 61 conventional nongrazing (CON-NG) herds located in New York State, Oregon, and Wisconsin. Rate of pneumonia differed among grazing systems $(P<0.001)$.

any cases of ketosis during the data collection period for their farm. The overall rate of farmer-identified and recorded cases of ketosis ranged from 0 to 0.64 cases per 305 lactating cow-days, and was greater in CON-NG herds compared with CON-GR and ORG (Figure 2). Explanatory variables unconditionally associated with an increase in rate of farmer-identified and recorded cases of ketosis $(P<0.20)$ included greater RHA and greater amount of grain fed. Increased rates of ketosis were also unconditionally associated with the categories CON-NG farm type, large herd size, stall barn housing, farmer reporting high or intermediate likelihoods of calling a veterinarian for an off-feed cow, farmer perceiving ketosis to occur on the farm, many routinely scheduled veterinary visits per 100 cows per year, farms located in WI, and testing for ketosis as part of a routine postpartum cow exam. An increased rate of ketosis was unconditionally associated with the farmer's definition of ketosis including any of the following: (1) positive ketone test, (2) depressed attitude, (3) decreased milk production, (4) decreased feed intake, and (5) signs of nervous ketosis. The rate of ketosis was not associated with predominant breed present on the farm or with season of herd visit.

Of the explanatory variables unconditionally associated with rate of farmer-identified and recorded cases of ketosis, primary housing for lactating cows, routinely checking postpartum cows for ketosis, definition of ketosis including depressed attitude, farmer perceiving ketosis to occur on farm, an interaction between grazing system and amount of grain fed, and an interaction between grazing system and definition of ketosis includ- ing decreased milk production remained in the final multivariate model, and site and herd size were forced into the final multivariate model (Table 6). The AIC of the final multivariate model was 398 , with a Pearson $\chi^{2}$ of 254 and 262 degrees of freedom.

The effect of grazing system depended on definition of ketosis and amount of grain fed. Among CON-NG farmers, including decreased milk production in their definition of ketosis was associated with increased rates of ketosis in their herds; among CON-GR farmers, the rate of ketosis in their herd was similar regardless of inclusion of decreased milk production in the definition of ketosis. In contrast, ORG farmers who included decreased milk production in their definition of ketosis had decreased rates of ketosis in their herds compared with ORG farmers who did not include decreased milk production in their definition of ketosis. Among all farm types, increasing the amount of grain fed was associated with increased rates of ketosis, but this effect was approximately 3 times greater on CON-GR compared with ORG and CON-NG farms. The rate of ketosis was least in herds with freestall and group pen housing, and about 3 times greater in herds with stall barn housing. Farmers located in WI and OR identified and recorded greater rates of ketosis compared with farmers in NY. Farmers who included depressed attitude in their definition of ketosis identified and recorded 2.5 times greater rates of ketosis compared with farmers who did not include depressed attitude in their definition of ketosis. Farmers who either did not perceive ketosis to ever occur on their farm or were unable to define ketosis were 20 times more likely to report zero cases of ketosis during the data collection period compared with farmers who perceived ketosis to occur on their farm.

\section{Rate of Pneumonia}

Data included in the analysis of rate of farmer-identified and recorded cases of pneumonia were from farmers who returned data for either the retrospective or combined data collection periods $(\mathrm{n}=187$ ORG, $\mathrm{n}=34$ CON-GR, and $n=61$ CON-NG). Of farmers included in the analysis, $216(76 \%)$ did not identify and record any cases of pneumonia during the data collection period for their farm. The overall rate of farmer-identified and recorded cases of pneumonia ranged from 0 to 0.43 cases per 365 cow-days, and was least for CON-GR herds compared with CON-NG and ORG (Figure 3). Explanatory variables unconditionally associated with an increase in rate of pneumonia $(P<0.20)$ included medium or large herd size, a greater proportion of lactating and dry cows in third or greater lactation, and a lesser proportion of cows in early lactation. Increased rates of pneumonia were also unconditionally associ- 
PERCEPTIONS AND RISK FACTORS FOR DISEASE

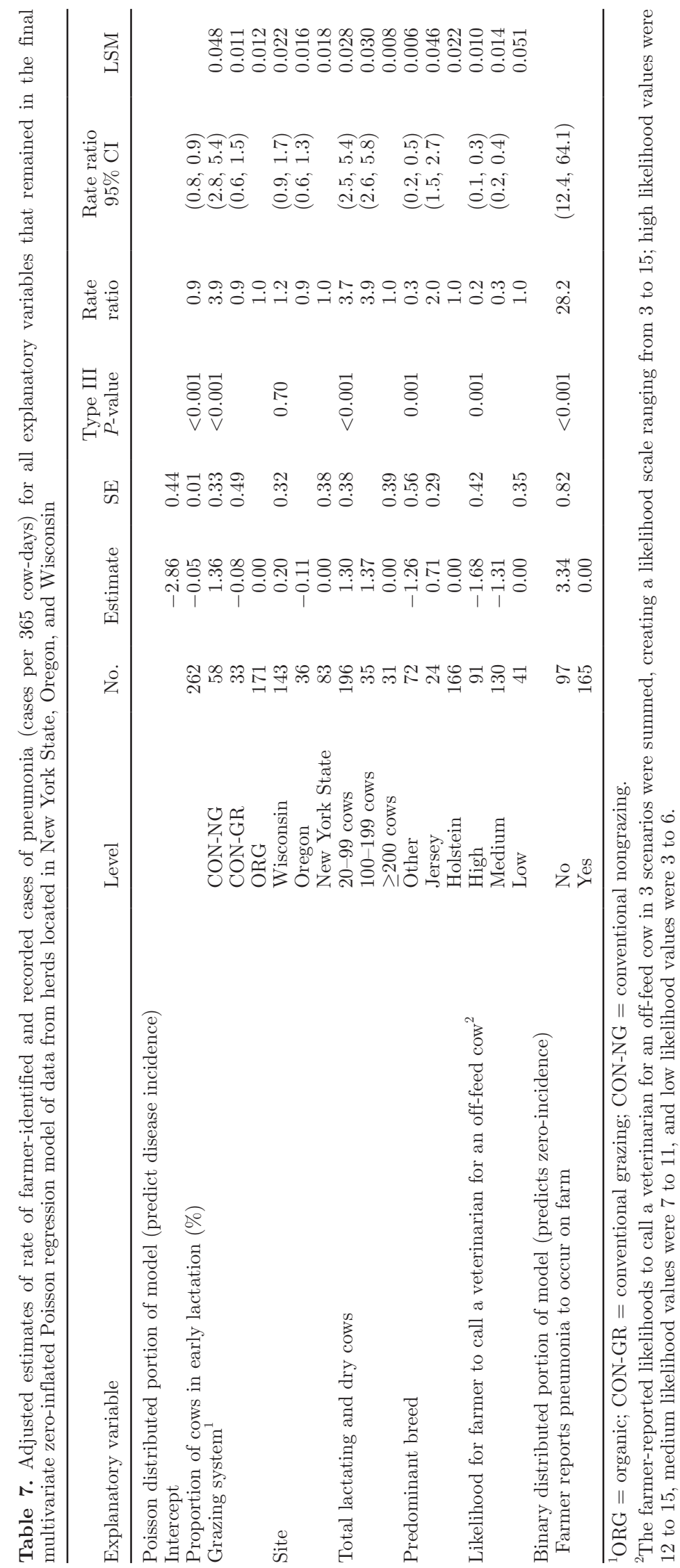


ated with the categories Jersey as the predominant breed, low likelihood of calling a veterinarian for an off-feed cow, many routinely scheduled veterinary visits per 100 cows per year, farmer perceiving pneumonia to occur on farm, and stall barn housing. An increased rate of pneumonia was unconditionally associated with the farmer's definition of pneumonia including any of the following: (1) cough, (2) nasal discharge, and (3) decreased milk production. A decreased rate of pneumonia was unconditionally associated with the farmer's definition of pneumonia including dyspnea. The rate of pneumonia was not associated with season of herd visit.

Of the risk factors unconditionally associated with the rate of pneumonia, grazing system, predominant breed, herd size, farmer-reported likelihood of calling a veterinarian for an off-feed cow, farmer perceiving pneumonia to occur on farm, and proportion of cows in early lactation remained in the final multivariate model, and site was forced into the final multivariate model (Table 7). The AIC of the final multivariate model was 319, with a Pearson $\chi^{2}$ of 259 and 248 degrees of freedom.

The rate of pneumonia was approximately 4 times greater on CON-NG compared with CON-GR and ORG farms. Farms with Holstein as the primary breed had rates of pneumonia 3 times as high as farms with other primary breeds and half as high as farms with Jersey as the primary breed. Farmers who reported a high or medium likelihood of calling a veterinarian had approximately 3 times lesser rates of pneumonia in their herds compared with farmers who reported a low likelihood of calling a veterinarian. Every 1\% increase in proportion of lactating cows in early lactation was associated with nine-tenths as great a rate of pneumonia. Farmers who either did not perceive pneumonia to ever occur on their farm or were unable to define pneumonia were 28 times more likely to report zero cases of pneumonia during the data collection period compared with farmers who perceived pneumonia to occur on their farm.

\section{DISCUSSION}

The herds that enrolled in this study represented small organic and conventional dairy herds located in 3 US states and the reference population consisted of herds of similar size that used similar management strategies. Use of routine, frequent monitoring of transition cows is often recommended to improve disease detection and treatment (Smith and Risco, 2005; LeBlanc, 2010). The failure to actively detect disease has been cited as contributing to reduced rates of farmerreported cases of mastitis (Gröhn et al., 2004) and lameness (Barker et al., 2010). In the current study, disease screening and definitions were assessed together with potential risk factors to determine their impact on rate of farmer-identified and recorded cases of disease. The use of farmer-identified and recorded data reflects disease incidence in the same way that it is perceived on commercial dairies. In a commercial setting, animal caregivers observe the animals to screen for disease, and they determine if an animal is sick and how to intervene. The use of farmer identified and recorded diseases also reflects the reality that few farmers use veterinarians for primary diagnoses of common diseases of dairy cows (Richert et al., 2013). Of farmers that reported the diseases of interest in this study, none used veterinarians to diagnose clinical mastitis, and only 2 , 10 , and $11 \%$ of farmers used veterinarians to diagnose calf pneumonia, pneumonia in adult cows, and ketosis, respectively (Richert et al., 2013).

The negative binomial distribution is an alternate method of modeling an overdispersed Poisson distribution and has been previously been described for clinical mastitis incidence rate data (Schukken et al., 1991). In the current data, the final multivariate model for rate of farmer-identified and recorded clinical mastitis fitted using the negative binomial distribution included similar variables as a model fitted using an overdispersed Poisson distribution, but the model fitted using the negative binomial distribution had improved goodness of fit, as evaluated by Pearson $\chi^{2}$ divided by degrees of freedom (1.10), compared with the model fitted using the overdispersed Poisson distribution (3.19). The zeroinflated Poisson distribution accounts for an excess of zeros in the data by modeling the data in 2 portions: (1) a Poisson-distributed portion that models the continuous count outcome and (2) a binary-distributed portion that models the probability of a zero outcome (Dohoo et al., 2003). The goodness of fit as evaluated by Pearson $\chi^{2}$ divided by degrees of freedom was improved in models fitted using the zero-inflated Poisson distribution for rate of farmer-identified and recorded ketosis (0.97) and pneumonia (1.04) compared with models fitted using an overdispersed Poisson distribution for rate of farmer-identified and recorded ketosis (1.39) and pneumonia (2.11). Although the rates of disease had negative binomial and Poisson, rather than normal, distributions, adjusted means are presented in the final models to aid in understanding and interpretation of the data.

Perception of disease (as indicated by disease definition and screening) was positively associated with the rate of clinical mastitis and ketosis. Farmers who listed abnormalities in the milk or udder as 1 of the 3 primary symptoms they rely on to screen for potentially ill cows were indicating that they perceived mastitis as an important health concern on their farm. However, this does not imply direction of association. Farmers who 
routinely experience many cases of mastitis may perceive mastitis as problematic (Jansen et al., 2009), or farmers who perceive mastitis as important may identify more mastitis cases (Nyman et al., 2007). Similarly, farmers who had a more sensitive definition of ketosis (that included depressed attitude) recorded increased rates of ketosis. Inclusion of decreased milk production as part of the definition of ketosis was associated with a 4-fold increase in rate of ketosis in CON-NG herds, no difference in CON-GR herds, and a decrease in ORG herds. This interaction may be due to greater difficulty in identifying decreased milk production in herds where cows have lower baseline milk yields.

Understanding and identification of disease influenced rate of disease. Farmers who reported during the interview that they either did not perceive ketosis or pneumonia to occur on their farm or could not define ketosis or pneumonia accordingly were 20 times more likely to record zero cases of ketosis or pneumonia during the data collection period. Farmers may perceive a disease to not occur on their farm either because the disease truly is not present or because they lack the understanding of the disease necessary for identification. When a farmer lacks understanding of the disease, it is quite likely that the disease is not recognized on the farm and a zero incidence would be the logical result. Routine examination of postpartum cows for mastitis and ketosis was associated with increased rates of clinical mastitis and ketosis, respectively. As the main goal of routine examination of postpartum cows is early detection and treatment of disease (Smith and Risco, 2005), it is intuitive that these examinations would also result in increased identification of mastitis and ketosis.

Interestingly, although authors of one previous study reported no difference in intestinal parasite burden between ORG and CON management systems (Sato et al., 2005), ORG farmers reported either perceiving parasites as a problem or routinely administering anthelmintics for adult cows and heifers less often as compared with CON farmers. It is possible that there is increased use of readily available anthelmintics among CON farmers. Conversely, it also is possible that a lack of knowledge or lack of prior experience with alternative therapies may influence the willingness of ORG farmers to treat for parasites, similar to a previous report for mastitis treatment on ORG farms (Vaarst et al., 2002).

Conventionally managed herds had greater rates of ketosis compared with herds with ORG management, similar to findings of previous researchers (Hardeng and Edge, 2001; Bennedsgaard et al., 2003b; Valle et al., 2007). Conventionally managed herds also had greater milk yield compared with herds with ORG management, which is associated with a greater risk of negative energy balance in early lactation (Rasmussen et al.,
1999; Divers and Peek, 2008; Fall et al., 2008). This study also quantified the effect of some differences in nutritional management among grazing systems. Farmers who used grazing (CON-GR and ORG) identified and recorded decreased rates of ketosis compared with CON-NG farmers. Along with increased forage content of the diet, grazing may lead to decreased milk yield through increased energy expenditure (Kaufmann et al., 2011). Although increasing amounts of grain fed was associated with increased rates of ketosis in all grazing systems, this effect was greater in herds with CONGR management compared with ORG and CON-NG. Increased amounts of concentrates in the diet may lead to greater milk yield (Kuoppala et al., 2004) and have previously been associated with an increased risk of ketosis (Gustafsson et al., 1995). The effect of increased grain may be greater in CON-GR herds if CON-GR farmers are more likely to feed concentrates separately from forage compared with ORG and CON-NG herds (Østergaard and Gröhn, 2000).

Farmers utilizing CON management identified and recorded greater rates of clinical mastitis compared with ORG farmers, similar to previous reports (Hardeng and Edge, 2001; Pol and Ruegg, 2007; Valle et al., 2007). The final model was adjusted for several factors that may differ among management systems and thus may act as potential confounders, including bulk tank SCC (Hardeng and Edge, 2001; Zwald et al., 2004) and type of housing (Zwald et al., 2004; Sato et al., 2005). However, other possible factors that were not included in the final model and may have contributed to the lesser rates of clinical mastitis observed on ORG farms include genetic differences between ORG and CON cattle (Nash et al., 2000; Nauta et al., 2006), potential reporting bias due to decreased recording of alternative therapies administered by ORG farmers (Valle et al., 2007), and environmental effects such as differences in bedding type (Sato et al., 2005) or cleanliness (Barnouin et al., 2005; Green et al., 2007). Cow-level risk factors for mastitis such as stage of lactation (Sordillo, 2005), milk yield (Peeler et al., 2000), and parity (Green et al., 2007) were adjusted for at the herd level and did not remain in the final model.

Routine use of forestripping during the milking procedure was associated with increased rates of clinical mastitis, similar to results previously reported for mastitis caused by E. coli and Staphylococcus aureus (Elbers et al., 1998). This association is likely due to increased identification of mastitis cases because of proactive and more sensitive detection (Gröhn et al., 2004; Nyman et al., 2007).

Although seasonal effects have been reported for ketosis (Andersson and Emanuelson, 1985; Tveit et al., 1992), mastitis and SCC (Hogan and Smith, 2003; Ny- 
man et al., 2007; Olde Riekerink et al., 2007), and calf pneumonia (McGuirk, 2008), the effect of season of herd visit was not unconditionally associated with rate of any selected diseases in the current study. In this study, the rate of disease was measured over a $60-$ or $120-\mathrm{d}$ data collection period and herd visits occurred during a 24-mo period. The data collection period would have spanned multiple seasons for all herds that completed the combined data collection period and approximately one-third of herds that completed only the retrospective data collection period. Data collection that spans multiple seasons will reduce the effect of the season relative to the date in which the herd visit occurred.

Housing cows in stall barns was associated with increased rates of clinical mastitis, ketosis, and pneumonia, although the effect of housing did not remain in the final multivariate model for pneumonia. Increased age of facilities and smaller herd size were associated with stall barn housing and may act as confounders and explain a portion of the effect of stall barn housing. The rate of clinical mastitis was approximately 1.5 times as great for herds utilizing group or stall barn housing compared with freestall housing. It is likely that the effect of housing type is mediated through exposure to pathogens in bedding or indirect effect of housing on animal hygiene. The influence of bedding type (Hogan et al., 1989; Hogan and Smith, 2003), depth (Barkema et al., 1999), and cleanliness (Elbers et al., 1998; Barkema et al., 1999; Green et al., 2007) on the rate of clinical mastitis have been previously described. Use of clean and dry bedding minimizes the exposure of cow teats to bacterial pathogens and reduces risk of the cow developing clinical mastitis. Similar to previous reports, the rate of ketosis was twice as great in herds with stall barn housing compared with other types of housing (Valde et al., 1997; Simensen et al., 2010). The association between housing and ketosis is likely mediated through differences in feeding management (Simensen et al., 2010), with stall barn and pasture herds more likely to utilize component feeding compared with TMR feeding, and therefore at greater risk of ketosis (Østergaard and Gröhn, 2000). Herds that utilized grazing (CONGR and ORG) had 4-fold decreased rates of pneumonia compared with $\mathrm{CON}-\mathrm{NG}$ herds, which potentially demonstrates the importance of air quality in managing pneumonia (Divers and Peek, 2008).

\section{CONCLUSIONS}

Perception of disease was similar among grazing systems and influenced the recorded rate of disease. Future studies of disease rates should account for methods of disease detection and differences in disease definition and perception. Greater rates of farmer-identified and recorded disease were associated with farmers who perceived mastitis as important or who had a more sensitive definition of ketosis. Other risk factors associated with increased rates of farmer-identified and recorded disease included proactive detection of disease (such as routine forestripping and examination of postpartum cows for mastitis and ketosis), stall barn housing, and use of CON management system. The effects of management system were mediated through risk factors such as amount of concentrate fed for ketosis rate and use of grazing for ketosis rate and pneumonia rate. Farmers who have similar-sized herds and use similar management strategies can manage these risk factors to reduce rates of mastitis, ketosis, and pneumonia on their farms.

\section{ACKNOWLEDGMENTS}

This study was funded by the USDA NIFA project 2008-51106-19463, "Impact of Organic Management on Dairy Animal Health and Well-being."

\section{REFERENCES}

Andersson, L., and U. Emanuelson. 1985. An epidemiologic study of hyperketonemia in Swedish dairy cows-Determinants and the relation to fertility. Prev. Vet. Med. 3:449-462.

Barkema, H. W., Y. H. Schukken, T. J. Lam, M. L. Beiboer, G. Benedictus, and A. Brand. 1999. Management practices associated with the incidence rate of clinical mastitis. J. Dairy Sci. 82:1643-1654.

Barker, Z. E., K. A. Leach, H. R. Whay, N. J. Bell, and D. C. J. Main. 2010. Assessment of lameness prevalence and associated risk factors in dairy herds in England and Wales. J. Dairy Sci. 93:932-941.

Barnouin, J., S. Bord, S. Bazin, and M. Chassagne. 2005. Dairy management practices associated with incidence rate of clinical mastitis in low somatic cell score herds in France. J. Dairy Sci. 88:3700-3709.

Bennedsgaard, T. W., C. Enevoldsen, S. M. Thamsborg, and M. Vaarst. 2003a. Effect of mastitis treatment and somatic cell counts on milk yield in Danish organic dairy cows. J. Dairy Sci. 86:31743183.

Bennedsgaard, T. W., S. M. Thamsborg, M. Vaarst, and C. Enevoldsen. 2003b. Eleven years of organic dairy production in Denmark: Herd health and production related to time of conversion and compared to conventional production. Livest. Prod. Sci. 80:121-131.

Bruun, J., A. K. Ersboll, and L. Alban. 2002. Risk factors for metritis in Danish dairy cows. Prev. Vet. Med. 54:179-190.

Divers, T. J., and S. F. Peek. 2008. Rebhun's Diseases of Dairy Cattle. 2nd ed. Saunders, Elsevier, St. Louis, MO.

Dohoo, I., W. Martin, and H. Stryhn. 2003. Veterinary Epidemiologic Research. AVC Inc., Charlottetown, PEI, Canada.

Elbers, A. R. W., J. D. Miltenburg, D. De Lange, A. P. P. Crauwels, H. W. Barkema, and Y. H. Schukken. 1998. Risk factors for clinical mastitis in a random sample of dairy herds from the southern part of the Netherlands. J. Dairy Sci. 81:420-426.

Ellis, K. A., G. T. Innocent, M. Mihm, P. Cripps, W. G. McLean, C. V. Howard, and D. Grove-White. 2007. Dairy cow cleanliness and milk quality on organic and conventional farms in the UK. J. Dairy Res. 74:302-310.

Fall, N., Y. T. Grohn, K. Forslund, B. Essen-Gustafsson, R. Niskanen, and U. Emanuelson. 2008. An observational study on early-lactation metabolic profiles in Swedish organically and conventionally managed dairy cows. J. Dairy Sci. 91:3983-3992. 
Green, M. J., A. J. Bradley, G. F. Medley, and W. J. Browne. 2007. Cow, farm, and management factors during the dry period that determine the rate of clinical mastitis after calving. J. Dairy Sci. 90:3764-3776.

Gröhn, Y. T., D. J. Wilson, R. N. Gonzalez, J. A. Hertl, H. Schulte, G. Bennett, and Y. H. Schukken. 2004. Effect of pathogen-specific clinical mastitis on milk yield in dairy cows. J. Dairy Sci. $87: 3358-3374$.

Gustafsson, A. H., L. Andersson, and U. Emanuelson. 1995. Influence of feeding management, concentrate intake and energy intake on the risk of hyperketonaemia in Swedish dairy herds. Prev. Vet. Med. 22:237-248.

Hardeng, F., and V. L. Edge. 2001. Mastitis, ketosis, and milk fever in 31 organic and 93 conventional Norwegian dairy herds. J. Dairy Sci. 84:2673-2679.

Hill, A. E., A. L. Green, B. A. Wagner, and D. A. Dargatz. 2009. Relationship between herd size and annual prevalence of and primary antimicrobial treatments for common diseases on dairy operations in the United States. Prev. Vet. Med. 88:264-277.

Hogan, J., and K. L. Smith. 2003. Coliform mastitis. Vet. Res. 34:507-519.

Hogan, J. S., K. L. Smith, K. H. Hoblet, D. A. Todhunter, P. S. Schoenberger, W. D. Hueston, D. E. Pritchard, G. L. Bowman, L. E. Heider, B. L. Brockett, and H. R. Conrad. 1989. Bacterial counts in bedding materials used on 9 commercial dairies. J. Dairy Sci. 72:250-258.

Jansen, J., B. H. P. van den Borne, R. J. Renes, G. van Schaik, T. Lam, and C. Leeuwis. 2009. Explaining mastitis incidence in Dutch dairy farming: The influence of farmers' attitudes and behaviour. Prev. Vet. Med. 92:210-223.

Kaufmann, L. D., A. Münger, M. Rérat, P. Junghans, S. Görs, C. C. Metges, and F. Dohme-Meier. 2011. Energy expenditure of grazing cows and cows fed grass indoors as determined by the ${ }^{13} \mathrm{C}$ bicarbonate dilution technique using an automatic blood sampling system. J. Dairy Sci. 94:1989-2000.

Kuoppala, K., S. Yrjanen, S. Jaakkola, R. Kangasniemi, J. Sariola, and H. Khalili. 2004. Effects of increasing concentrate energy supply on the performance of loose-housed dairy cows fed grass silage-based diets. Livest. Prod. Sci. 85:15-26.

LeBlanc, S. 2010. Monitoring metabolic health of dairy cattle in the transition period. J. Reprod. Dev. 56:S29-S35.

McGuirk, S. M. 2008. Disease management of dairy calves and heifers. Vet. Clin. North Am. Food Anim. Pract. 24:139-153.

Nash, D. L., G. W. Rogers, J. B. Cooper, G. L. Hargrove, J. F. Keown, and L. B. Hansen. 2000. Heritability of clinical mastitis incidence and relationships with sire transmitting abilities for somatic cell score, udder type traits, productive life, and protein yield. J. Dairy Sci. 83:2350-2360.

Nauta, W. J., R. F. Veerkamp, E. W. Brascamp, and H. Bovenhuis. 2006. Genotype by environment interaction for milk production traits between organic and conventional dairy cattle production in the Netherlands. J. Dairy Sci. 89:2729-2737.

Nyman, A. K., T. Ekman, U. Emanuelson, A. H. Gustafsson, K. Holtenius, K. P. Waller, and C. H. Sandgren. 2007. Risk factors associated with the incidence of veterinary-treated clinical mastitis in Swedish dairy herds with a high milk yield and a low prevalence of subclinical mastitis. Prev. Vet. Med. 78:142-160.

Olde Riekerink, R. G. M., H. W. Barkema, and H. Stryhn. 2007. The effect of season on somatic cell count and the incidence of clinical mastitis. J. Dairy Sci. 90:1704-1715.

Østergaard, S., and Y. T. Gröhn. 2000. Concentrate feeding, dry-matter intake, and metabolic disorders in Danish dairy cows. Livest. Prod. Sci. 65:107-118.

Peeler, E. J., M. J. Green, J. L. Fitzpatrick, K. L. Morgan, and L. E. Green. 2000. Risk factors associated with clinical mastitis in low somatic cell count British dairy herds. J. Dairy Sci. 83:2464-2472.
Pol, M., and P. L. Ruegg. 2007. Treatment practices and quantification of antimicrobial drug usage in conventional and organic dairy farms in Wisconsin. J. Dairy Sci. 90:249-261.

Radostits, O. M., C. C. Gay, K. W. Hinchcliff, and P. D. Constable. 2007. Veterinary Medicine: A Textbook of the Diseases of Cattle, Horses, Sheep, Pigs and Goats. 10th ed. Elsevier, Philadelphia, PA.

Rasmussen, L. K., B. L. Nielsen, J. E. Pryce, T. T. Mottram, and R. F. Veerkamp. 1999. Risk factors associated with the incidence of ketosis in dairy cows. Anim. Sci. 68:379-386.

Richert, R. M., K. M. Cicconi, M. J. Gamroth, Y. H. Schukken, K. E. Stiglbauer, and P. L. Ruegg. 2013. The role of the veterinarian on organic and conventional dairy farms. J. Am. Vet. Med. Assoc. In press.

Rodrigues-Motta, M., D. Gianola, B. Heringstad, G. J. M. Rosa, and Y. M. Chang. 2007. A zero-inflated Poisson model for genetic analysis of the number of mastitis cases in Norwegian Red cows. J. Dairy Sci. 90:5306-5315.

Ruegg, P. L. 2009. Management of mastitis on organic and conventional dairy farms. J. Anim. Sci. 87:43-55.

SAS Institute. 2011. SAS/STAT User's Guide. Version 9.3. SAS Institute Inc., Cary, NC.

Sato, K., P. C. Bartlett, R. J. Erskine, and J. B. Kaneene. 2005. A comparison of production and management between Wisconsin organic and conventional dairy herds. Livest. Prod. Sci. 93:105-115.

Schreiner, D. A., and P. L. Ruegg. 2003. Relationship between udder and leg hygiene scores and subclinical mastitis. J. Dairy Sci. 86:3460-3465.

Schukken, Y. H., G. Casella, and J. d. Broek. 1991. Overdispersion in clinical mastitis data from dairy herds: A negative binomial approach. Prev. Vet. Med. 10:239-249.

Simensen, E., O. Østerås, K. E. Boe, C. Kielland, L. E. Ruud, and G. Naess. 2010. Housing system and herd size interactions in Norwegian dairy herds; associations with performance and disease incidence. Acta Vet. Scand. 52:14.

Smith, B. I., and C. A. Risco. 2005. Management of periparturient disorders in dairy cattle. Vet. Clin. North Am. Food Anim. Pract. 21:503-521.

Smith, B. P. 2008. Large Animal Internal Medicine. 4th ed. Mosby, St. Louis, MO.

Sordillo, L. M. 2005. Factors affecting mammary gland immunity and mastitis susceptibility. Livest. Prod. Sci. 98:89-99.

Stiglbauer, K. E., K. M. Cicconi, R. Richert, Y. H. Schukken, P. L. Ruegg, and M. Gamroth. 2013. Assessment of herd management on organic and conventional dairy farms in the United States. J. Dairy Sci. 96:1290-1300.

Tveit, B., F. Lingaas, M. Svendsen, and Ø. V. Sjaastad. 1992. Etiology of acetonemia in Norwegian cattle. 1. Effect of ketogenic silage, season, energy level, and genetic factors. J. Dairy Sci. 75:24212432 .

Vaarst, M., B. Paarup-Laursen, H. Houe, C. Fossing, and H. J. Andersen. 2002. Farmers' choice of medical treatment of mastitis in Danish dairy herds based on qualitative research interviews. J. Dairy Sci. 85:992-1001.

Valde, J. P., D. W. Hird, M. C. Thurmond, and O. Østerås. 1997. Comparison of ketosis, clinical mastitis, somatic cell count, and reproductive performance between free stall and tie stall barns in Norwegian dairy herds with automatic feeding. Acta Vet. Scand. 38:181-192.

Valle, P. S., G. Lien, O. Flaten, M. Koesling, and M. Ebbesvik. 2007. Herd health and health management in organic versus conventional dairy herds in Norway. Livest. Sci. 112:123-132.

Zwald, A. G., P. L. Ruegg, J. B. Kaneene, L. D. Warnick, S. J. Wells, C. Fossler, and L. W. Halbert. 2004. Management practices and reported antimicrobial usage on conventional and organic dairy farms. J. Dairy Sci. 87:191-201 